\title{
State Practice of Asian Countries in International Law
}

Vietnam

\author{
Tran Viet Dung*
}

\section{Criminal LaW - Cybersecurity - Development of the LEgal Framework For CyBERSECURITY IN VietNAM}

With the increasing cross-border cyber-attacks adversely affecting both public and private sectors, the development of a legal framework for cybersecurity has become a significant concern of governments around the world. Vietnam has been historically weak when it comes to cybersecurity and has been ranked among the bottom regionally. According to a report by the Report Global Cyber Security Index 2017 by the International Telecommunications Union, Vietnam ranked 101 out of 165 countries in terms of being vulnerable to cyber-attacks. To that end, in June 2018, the National Assembly of Vietnam passed the Law on Cybersecurity, which has taken effective as of 1 January 2019.

The Law on Cybersecurity covers all networks of IT infrastructure, telecommunication, internet, computer systems, databases, information processing, storage, and controlling systems, and regulates activities of every enterprise providing services in cyberspace and internet users including e-commerce, websites, online forums, social networking, and blogs. The Law applies to all agencies, organizations, and individuals involving in the cyberspace causing harm to national security, social order, and safety. In particular, it will apply to overseas organizations, which have users residing in Vietnam such as Google or Facebook. It is observed that the new law's provisions echoes recent aggressive moves conducted by the Europe Union's General Data Protections Regulation (GDPR) and China's cybersecurity law that dictate how foreign organizations can operate in their respective region's and how citizen information will be handled, processed, stored, and secured.

The Law on Cybersecurity prohibits five types of information that are prohibited in cyberspace, including information opposing the State of the Socialist Republic of Vietnam; information inciting others to cause disturbances or disrupt security and public order; information humiliating or slandering

* Associate Professor, Dean of International Law Faculty, Ho Chi Minh City University of Law, Vietnam. 
others; information infringing upon the economic management order; and fabricated or untrue information causing public anxiety or harms to socioeconomic activities or difficulties to operations of state agencies or on-duty persons or infringing upon lawful rights and interests of others. Domestic and foreign enterprises that provide services in telecommunications networks or the internet or provide added-value services in cyberspace in Vietnam have to prevent the sharing of the above-said information on their service platforms or information systems within 24 hours after receiving a request from competent authorities. In addition, they must refrain from providing or suspend the provision of telecommunications or internet-based services and other addedvalue services to organizations and individuals that publish in cyberspace such information when so requested by competent authorities.

In addition, the Law on Cybersecurity also imposes data localization requirements. Accordingly, "personal information", "data of relations of services users", "data created by service users" in Vietnam collected, analyzed, processed by either domestic or foreign enterprises providing services in the telecommunication network, internet, and value-added services in cyberspace in Vietnam must be stored in Vietnam. Vietnam's Ministry of Public Security, in a statement released on its website, explains that such requirements are needed in order to better manage and protect data on the cyber environment, especially in the context when data of local users have been rampantly used for commercial purposes and even abused to serve political plots or illegal activities.

\section{United Nations - Foreign Affairs Activities - Vietnam's Election as a Security Council Non-Permanent Member for 2020-2021}

On 7 June 2019, Vietnam was elected as a non-permanent member of the UN Security Council (UNSC) for the term 2020-2021 with a record-high number of 192 votes out of the 193 member countries and territories of the UN General Assembly. ${ }^{1}$ As regulated, Vietnam would officially assume the role as a nonpermanent member of the UNSC as of 1 January 2020.

This is the second time Vietnam has been elected to the United Nations Security Council, after its first term on the Council in 2008-2009. Vietnam's contributions and performance of the duties during the first time serving

1 Vietnam was the only representative of the Asian-Pacific region to run for the post, receiving the highest votes in favour (Nigeria and Tunisia both received 191 votes, Saint Vincent and the Grenadines 185 votes, and Estonia 132 votes). 
on the UNSC have been widely recognized and appreciated, which certainly helped the nation obtain high confidence from other countries as Vietnam ran for the position for the second time which was evident by the landslide vote.

The election proves that after over three decades of reforms and integration, the credential and role of Vietnam in the global arena and within the United Nations have been increasing. The international community has recognized the contributions of the country in regional and international engagement in promoting cooperation and peaceful settlement of international disputes.

Vietnam has been implementing a foreign policy of peace and made contributions to addressing world conflicts and crises while backing peaceful negotiations and restriction of sanctions based on international law and principles of the UN Charter. According to UN Resident Coordinator in Vietnam Kamal Malhotra, with the election to the UNsc, Vietnam will have more opportunities to prove its ability and play an important role in regional and global events.

As a matter of fact, since 2010, Vietnam has demonstrated active participation in the activities of the UNSC. Apart from fully participating in over 1,500 meetings of the UNSC, the Vietnamese delegation became actively involved in all matters and at all stages of work on the Council, through making speeches, joining in negotiations, contributing to the drafting of resolutions and documents, and serving as chair and vice-chair of some subcommittees of the Council. In particular, Vietnam chaired the negotiations and compilation of the Council's resolution on women and security peace. As a representative of Southeast Asia, Vietnam pushed the peaceful settlement of regional issues as well as matters in other regions like Africa and the Middle East. In particular, Vietnam sent 172 military officers and staff to UN peacekeeping missions in the Central African Republic and South Sudan, as well as the Department of Peacekeeping Operations at UN headquarters. Vietnam has also signed nine memoranda of understanding on UN peacekeeping cooperation with various partner countries; namely, Australia, China, France, India, Japan, New Zealand, Russia, South Korea, and the United States. Vietnam was also able to flexibly handle its relations with powerful countries and those with common interests and traditional relations based on respecting and protecting the legitimate interests of stakeholders.

Becoming a UNSC non-permanent member for 2020-2021 is an important milestone in Vietnam's implementation of the 12th National CPV Congress Resolution which guides its multilateral diplomatic work to "proactively integrate into and promote the country's role in multilateral mechanisms, especially ASEAN and the UN". According to Deputy Prime Minister and 
Minister of Foreign Affairs Pham Binh Minh, in its second term at the UNSC, Vietnam would stress the status of multilateralism and compliance with international law in addressing global challenges regarding peace and security in the world. In addition, as the chair of the ASEAN in 2020, Vietnam will seek to further enhance the cooperation between the UNSC and regional organizations, including ASEAN.

\section{INTERNATIONAL ECONOMIC LAW - Adoption OF THE NEW LABOr Code IN LiNe With INTERNATIONAL LAW}

The new Labor Code Amendment was passed by Vietnam's National Assembly (NA) on 20 November 2019 after multiple consultations with the public and discussions at the NA meetings since its first draft was introduced in late 2016 ("Labor Code 2019"). One of the main purposes of the adoption of the Labor Code 2019 is to ensure the effective implementation of the two important new generation free trade agreements of Vietnam, namely the Comprehensive and Progressive Agreement for Trans-Pacific Partnership (СP-TPP) and the European Union-Vietnam Free Trade Agreement (EVFTA). These FTAs provide a separate chapter on labor, which requires the signing parties to undertake to comply with the International Labor Organization (ILO) Conventions on Fundamental Principles and Rights at Work and its Follow-up, adopted by the ILO Conference in 1998.

The ILO Conventions promote the development of a national legal framework on labor relationship to promote the protection of the employees, i.e. (i) the freedom of association and the effective recognition of the right to collective bargaining; (ii) the elimination of all forms of forced or compulsory labor; (iii) the effective abolition of child labor; and (iv) the elimination of discrimination in respect of employment and occupation. The EFTA and CPTPP require the signatories to make continued and sustained efforts towards ratifying, to the extent it has not yet done so, the fundamental ILO conventions. Vietnam has ratified six of the ILo Conventions with the remaining two - Convention 105 on forced labor and Convention 87 on freedom association - due to be ratified in 2020 and 2023 .

The Labor Code 2019 creates an improved legal framework for employment relations, working conditions, and the representation of employers and workers. It also places greater emphasis on the use of voluntary collective negotiations, which are required for a modern socialist-oriented market economy in the process of deeper global integration. One of the most significant 
changes in the Labor Code 2019 compared to previous versions is the ability of workers in enterprises in Vietnam to exercise their right to form or join a representative organization of their choosing, which does not have to be affiliated to Vietnam's General Confederation of Labor. Freedom of association of labor union helps to improve the collective bargaining process that enables workers to get a fairer share of the profits and enterprises to negotiate the productivity improvements necessary for them. This is also a requirement under Clause 19.3(a) of the CPTPP and Clause 13.4(a) of the EVFTA.

The progress can be also observed in new definitions for discrimination and harassment and new freedoms given to workers to leave their job upon the condition of giving appropriate notice. The law also provides clearer guidance relating to forced labor and minor workers, which makes it easier for employers to understand what is and is not permitted and should enhance the ability of labor inspectors to advise and enforce in these areas.

Together with freedom of association, eliminating discrimination, child labor, forced labor are the four principles set out in the eight ILO fundamental Conventions enshrined in the 1998 Declaration. The Labor Code 2019 shall pave the way for the move towards the full realization of the 1998 ILO Declaration in Vietnam as it provides a better legal framework for employment and industrial relations, and for equitable and sustainable growth. The adoption of the new Labor Code represents significant steps of Vietnam towards alignment to all the internationally recognized fundamental principles.

\section{LAW Of The SEA - Treaties - Agreements Signed by Vietnam in 2019 - Protection of National Independence SOVEREIGNTY - SigNing THE SUPPLEMENTARY TREATY ON THE Delimitation of National Boundaries betWeEN Vietnam AND CAMBOdia}

On October 5, 2019, Vietnam and Cambodia signed the Supplementary Treaty to the 1985 Treaty on the Delimitation of National Boundaries and the Supplementary Treaty to the 2005 treaty (known as the 2019 Supplementary Treaty), and the protocol on land border demarcation and marker planting. This is the outcome of the effort and work of the joint working group on border gate issues on land border delimitation of the two countries over the last decade.

Deputy Prime Minister and Foreign Minister Pham Binh Minh described the signing of the 2019 Supplementary Treaty and the protocol as a major event 
in the bilateral relationship and a historic milestone in the process of the settlement of land border issues between Vietnam and Cambodia after more than 36 years of negotiations.

The National Assembly also adopted the resolution on the ratification of the 2019 Supplementary Treaty at the eighth session in 2019. The resolution formed a solid legal framework for the management and development of the Vietnam-Cambodia borderline, ensuring the maintenance of security, national defense, and social order and safety in the border region. It is expected that Vietnam and Cambodia will conduct border management according to the results of demarcation and landmarks more intensively in accordance with the Treaty. To date, the two sides have demarcated about 1,045 $\mathrm{km}$ of the border and built 2,047 markers at 4,553 positions in the field, i.e. around 84 percent of the workload along the entire border. These efforts have contributed to stabilizing and boosting socio-economic development, especially improving the economic, cultural, and social lives of border residents, creating a solid foundation for developing borderlines of peace, stability, friendship, cooperation, and sustainable development between Vietnam and Cambodia. 